\title{
A 20 años de la Ley del Procedimiento Administrativo General ${ }^{(*)}$
}

Juan Carlos Morón URbina

Abogado por la Universidad San Martín de Porres. Maestría en Derecho Constitucional por la Pontificia Universidad Católica del Perú. Doctor en Derecho por la Universidad de La Coruña, España. Profesor Ordinario de Derecho Administrativo en la Pontificia Universidad Católica del Perú. Miembro de la Comisión que elaboró el Anteproyecto de la Ley del Procedimiento Administrativo General.

Jorge Danós Ordóñez

Abogado por la Pontificia Universidad Católica del Perú. Maestría en Derecho Constitucional por la Pontificia Universidad Católica del Perú. Doctor en Derecho Constitucional por la Universidad Complutense de Madrid. Profesor Principal de Derecho Administrativo en la Pontificia Universidad Católica del Perú. Presidente de la Comisión que elaboró el Anteproyecto de la Ley de Procedimiento Administrativo General.

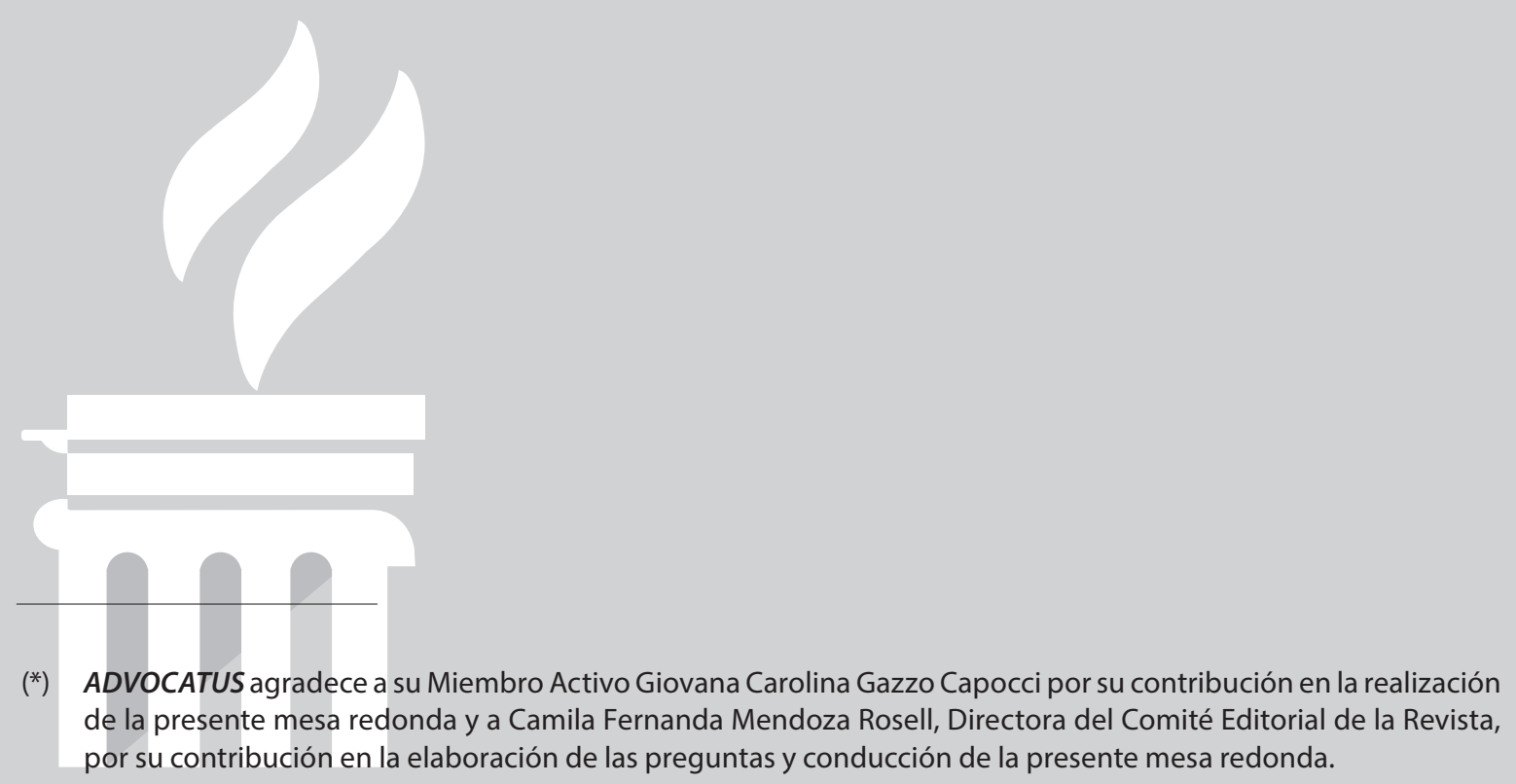




\section{RESUMEN:}

ADVOCATUS tuvo la oportunidad de reunirse y conversar con dos abogados peruanos, de gran trayectoria, especialistas en Derecho Administrativo, para que nos compartan sus reflexiones sobre la Ley del Procedimiento Administrativo General 20 años después de su promulgación.

Palabras clave: Derecho Administrativo, Ley del Procedimiento Administrativo General, entrevista

\section{ABSTRACT:}

ADVOCATUS had the opportunity to meet with two Peruvian lawyers of great experience in the administrative law field so that they could share their reflections on the Peruvian General Administrative Procedure Law — LPAG, 20 years after its enactment.

Keywords: Administrative Law, General Administrative Procedure Law, interview

1. Tras 20 años de la promulgación de la Ley del Procedimiento Administrativo General -en adelante, LPAG o Ley- ¿considera usted que su promulgación fue acertada respecto a la regulación anterior en materia administrativa?

Juan Carlos Morón Urbina (JCM): Antes de la LPAG, teníamos una norma que venía del año 1967: el Reglamento de Normas Generales del Proceso Administrativo. En 1992 fue elevada a rango de ley, pero era una norma bastante corta, que además se declaraba a sí misma como una norma supletoria a todas las disposiciones que tenían las entidades. Entonces, en la práctica lo que se tenía era una gran dispersión normativa, porque cada entidad tenía su propio reglamento, sus propias formas de conectarse con los ciudadanos, plazos distintos, requisitos distintos, etcétera.

No había ni siquiera un mínimo de uniformidad en la Administración Pública para que el ciudadano pueda tener un estatuto de derechos, ni había un mínimo de obligación de los funcionarios públicos hacia la administración. Tampoco había normas de organización como, por ejemplo, el tema de la competencia administrativa, la descentralización desconcentración, normas sobre como organizar algunos tipos de procedimientos como el sancionador, lo que era el trilateral, y la responsabilidad de los funcionarios no estaba centralizada en un cuerpo normativo.

Entonces, el cuerpo normativo que se dio bajo la Ley 27444 , creo que marcó un corte de lo que había antes a lo que vino después, porque era una norma que básicamente era pedagógica. Era extensa, sí, pero pedagógica. Centralizaba la regulación de todas las entidades públicas para dar un mínimo común a todas. Desde una municipalidad hasta un ministerio debían tener ese mismo régimen hacia los ciudadanos, por un tema de igualdad. Por la extensión de la norma y su carácter pedagógico también sirvió de generación de enseñanza, de estudios, de funcionarios públicos que se preparaban más, para ejercer mejor su función. Así también ha servido para generar un cuerpo de doctrina nacional y estudiosos del tema.

Entonces, creo que sí ha servido para generar un espacio para el Derecho Administrativo y para que la relación entre los ciudadanos y la administración sea mejor, más predecible y democrática.

Jorge Danós Ordoñez (JD): Yo sigo la saga del doctor Morón. Creo que hay una suerte de parteaguas, un antes y un después en la regulación del procedimiento administrativo en la ley. La LPAG, como ha comentado el doctor Morón, no es una ley que, vamos a decir así, viene de la nada porque teníamos precedentes. El Perú es el país en América Latina que se dota de la primera norma de procedimiento administrativo. La del año 1967 tomó en cuenta la ley española de 1956 y luego se complementó esa norma con la Ley de Simplificación Administrativa y con la Ley Marco de Crecimiento de la Inversión Privada. La LPAG, sin embargo, hace lo siguiente: es una ley que deliberadamente procura la 
garantía de los derechos de la persona en sede administrativa. Diría que hasta antes de la Ley el énfasis colocado era bueno, pues frente a la administración, en un procedimiento hay derechos. La administración debe actuar bien y si hay algún problema en las garantías estas se acceden ante el Poder Judicial, singularmente a través del amparo.

La lógica de la Ley es la siguiente: hay un conjunto de principios y derechos constitucionales, que vinculan a la administración, y esta debe guiar su actuación conforme a ellos. Eso lo vemos desde los principios del procedimiento administrativo. La Ley consagra y desarrolla los alcances de estos principios, que no son de organización ni de la estructura, son de la actuación administrativa. Hay que siempre tener en cuenta, como ha comentado el doctor Morón, que esta es una ley que está regulando la actuación de la administración, no la organización, ni la estructura, ni el aparato administrativo: está regulando cómo tiene que hacer la administración para cumplir sus funciones, para cumplir el rol que le asigna el ordenamiento jurídico.

Por eso, lo que hizo la LPAG fue consagrar un conjunto de principios, la mayor parte de ellos con fundamento constitucional pero no se quedó en el mero enunciado, no se quedó solamente en señalar el título, sino además hizo un desarrollo. Luego vino la jurisprudencia del Tribual Constitucional y ha habido una retroalimentación entre lo que la LPAG desarrolló y lo que la jurisprudencia amplió. Luego, la posterior reforma de la LPAG lo ha ido consagrando, así desde los principios hay una suerte de enfoque constitucional de lo que debe hacer la administración, de lo que tiene que respetar y cómo es que tiene que actuar en función de los derechos de los destinatarios de la actividad administrativa, que tienen a su vez consagradas garantías en la Ley.

La idea de toda ley de procedimiento administrativo es cómo poder aunar, equilibrar, armonizar el reconocimiento de prerrogativas exorbitantes a la administración - que no tenemos los privados- a fin de poder hacer viable la realización de los fines e intereses públicos. Por eso se le reconocen prerrogativas a la administración: estas son las prerrogativas públicas exorbitantes, pero siempre en consonancia, armonía y equilibrio con los derechos de las personas y por eso hay un conjunto de deberes. La sola existencia de un procedimiento administrativo es un mecanismo de control de la administración.

Si un país no tuviera regulado el procedimiento administrativo, la administración tendría deberes, potestades y actuaría a su aire. El procedimiento administrativo garantiza al destinatario que ese funcionario se va a ceñir a un cauce, que lo puede controlar y que tiene que respetar sus derechos. Por lo tanto, hay un fuerte énfasis en la Ley, como ha señalado el doctor Morón, de protección de garantías de los destinatarios desde una perspectiva constitucional, pero también recoge, como dijo el doctor Morón, un valor que es muy importante en nuestra legislación de procedimiento: simplificación administrativa. Recoge las normas precedentes, las moderniza y establece una serie de reglas de simplificación administrativa.

En el Perú seguimos hablando, a pesar de todo, del tema del burocratismo, del papeleo que hay, de las dificultades frente a la administración. Es un tema permanente, es un tema por el que hay que desterrar aspectos de la cultura administrativa que todavía se mantienen y que la Ley establece las armas, los mecanismos y empodera al ciudadano para poder reclamar esa simplificación administrativa.

Una ley no cambia la cultura, una ley no cambia la realidad, una ley lo que hace es establecer reglas para luego aplicarlas y además establece derechos para que se pueda reclamar. Eso hace la LPAG en una serie de aspectos, que ya no repito lo que trato el doctor Morón, en materia de la potestad sancionadora, entre otros.

Lo cierto es que, si la pregunta es, ¿ha sido importante? Sí, sí ha sido importante, porque enfatiza, vamos a decir así, este rol servicial de la administración que siempre debe mantener, enfatiza los aspectos constitucionales en la relación administración-ciudadano ciudada- 
no-administración, mantiene el valor siempre de la simplificación administrativa y procura lo que es normal, el estándar a nivel mundial, que es esta modernización entre el reconocimiento de potestades, prerrogativas a la administración para el cumplimiento de sus fines y derechos de los ciudadanos.

\section{Teniendo en cuenta nuestra tradición como país respecto a consolidar nuestras normas en códigos, ¿ustedes consideran que deberíamos dar el salto hacia un có- digo de derecho administrativo?}

JD: La LPAG en la práctica hace las veces casi de un código de Derecho Administrativo. Tengamos en cuenta, de un lado, que la LPAG es una ley transversal, que consagra un conjunto de principios de procedimiento que son transversales y así regula también. Por ejemplo, a lo que el doctor Morón se refirió del procedimiento administrativo trilateral, el procedimiento de fiscalización, el procedimiento y a la potestad sancionadora, igualmente, los regula con carácter transversal.

Por ejemplo, en materia sancionadora, si así vemos un símil, la Ley está consagrando lo que vendría ser la parte general del Código Penal, los principios y las reglas básicas del proceso. Entonces la Ley establece una regulación que vendría a ser lo que aplicado a otras ramas del derecho viene a ser una suerte de código, no digamos sustantivo porque la parte sustantiva es materia de regulación sectorial, pero que hace de código procesal. Regula el qué tiene que hacer la Administración Pública. El marco legal sustantivo le otorga competencias, potestades, le establece los parámetros para decidir, la LPAG le dice cómo hacer para que ese marco sustantivo se pueda ejecutar, se pueda llevar a la práctica y a la realidad. Eso es lo que hace la ley de procedimiento administrativo, es decir, ya la ley es un código de procedimiento administrativo.

El problema que hay en esa materia de procedimiento es que la tentación hoy día de las entidades es decir "no, yo quiero mi propia norma de procedimiento, yo me aparto de la ley".
Ello es obviamente contracorriente, porque la LPAG ha evolucionado -el doctor Morón ha participado- a ya no ser una mera ley general, sino ser una ley que además contiene normas comunes de procedimiento, y esas normas comunes de procedimiento, la idea es que sean también transversales.

Sin embargo, lo que ocurre es que, por comodidad y por un mal entendido afán de cumplir su rol o de entender que ellos son los justicieros y que las entidades cuando actúan correctamente siempre creen que la LPAG es muy garantista. Ese equilibrio que busca la Ley les impide cumplir sus funciones, ellos prefieren vivir cómodamente entendido que siempre actúan bien, y por tanto las garantías les caen mal. Las garantías "¿para qué?, si yo soy bueno y por tanto yo cumplo mis funciones, las garantías de la ley de procedimiento administrativo me dificultan", algo como que ¿los derechos para qué existen? Más o menos.

Lo relativo a la parte organizativa no es materia de un código, podría haber la iniciativa, como se planteó, de una suerte de ley general de la Administración Pública, ley general de organización, pero es muy difícil en nuestro régimen constitucional donde hay tres niveles de gobierno. En materia, ya la Ley de Procedimiento Administrativo hace las veces, en buena cuenta, de un código de procedimiento, o hace las veces de un código de carácter general de actuación de la Administración Pública.

JCM: Creo que en el Derecho Administrativo siempre ha habido una suerte de alergia, por decirlo de manera ilustrativa, al termino codificación. Ello porque se codifica, se estabiliza y se estanca. El Derecho Administrativo siempre se jacta de ser mutante, de ser adaptable, de ser variable en función de políticas de gobierno, en función de novedades tecnológicas, en función de necesidades de interés público. Esto a suerte de que, por ejemplo, en el Derecho Administrativo uno puede diferenciar desde el punto de vista de mutabilidad, dos partes. La parte que es más permanente en la Administración Pública que puede ser la teoría del acto administrativo, del procedimiento, los principios; $y$ otro 
gran componente del Derecho Administrativo pero muy variable, que son básicamente vinculados a, por ejemplo, telecomunicaciones, temas energéticos, a lo que llamamos el Derecho Administrativo especial.

Entonces ese Derecho Administrativo especial es muy variable, muy mutable y tiene normalmente una ley general y muchas normas directivas - que lo desarrollan. Entonces esa parte que es mutable, digamos, es imposible estancarla. No hay, que yo conozca, ningún país del mundo que trate de atascarlo en el tiempo con una ley, porque la ley lo hace invariable, entonces lo encarcelas y lo haces imposible de actualizarse.

Entonces, descartando la idea de la codificación en la parte especial del Derecho Administrativo, vamos a la parte central, a la parte, digamos, más estable que, como ya indiqué, es procedimiento, acto, recursos, simplificación, principios, organización administrativa. Esa parte sí es posible sistematizarla, pero tengo la impresión de que hay en la dogmática del Derecho Administrativo siempre el rechazo del concepto de código. De todos los países que yo recuerdo - por lo menos de habla hispana- el único que le llama código es Colombia, los demás lo llaman ley de Procedimiento Administrativo, ley de Administración Pública, pero el contenido es el mismo, es un código que contiene un montón de normas conexas, implicadas, sistematizadas, simplificadas en un cuerpo normativo único, pero no hay en Derecho Administrativo una ansia o un deseo de Ilamarle código. Siempre se le Ilama Ley General, Ley de Procedimientos o Ley de Procedimiento Administrativo. En Costa Rica, es la Ley General de la Administración Pública, en España es el Régimen de las Administraciones Públicas, pero no hay digamos esa idea de codificación.

Claro, funciona como un código virtualmente, algunos pueden hablar de Código Tributario, del Código Minero, del Código Procesal Civil, pero no perdamos de vista que ahí no está todo el Derecho Administrativo, el Derecho Administrativo queda gran parte por fuera, dis- perso y no codificable, porque es mutable. Normalmente se mueve a través de reglamentos, directivas, un tema muy especializado, que no se puede codificar por leyes.

3. La actividad de fiscalización es uno de los aspectos mas novedosos en la LPAG, pero también de los menos desarrollados ¿Qué mejoras considera usted que deben realizarse en el régimen de fiscalización? ¿Considera usted que existe desequilibrio entre la posición entre la Administración Pública y el administrado?

JCM: El régimen de la actividad de la fiscalización es uno de los últimos regímenes completos. Fue incorporado en la gran reforma que se ha hecho en la Ley, no estaba en la ley original. Desde esa perspectiva me parece que es una de las partes más recientes y yo no la tocaría, yo diría que hay que experimentar como va funcionando, porque la norma legal tiene que primero asentarse, los funcionarios públicos y los ciudadanos deben de sentirla propia y hacerla vivir para que funcione y ver que error hay, si hubiere.

Ahora yo te comento algo: cuando uno incorpora a ley general de una institución o la LPAG, es porque trata de regular lo común de todas las entidades. Es decir, no trata de sacar, por ejemplo, algo que funcione en el régimen pesquero, porque lo que funciona en el régimen pesquero no lo pasamos a la ley general. Ello porque cuando uno lo pone en la LPAG lo hace extensible a municipalidades, a regiones, a ministerios, lo extiendes a todos lados. Entonces cuando uno regula algo en la LPAG es porque ya está suficientemente maduro, utilizado por todas las entidades, es común y uno puede, digamos, de alguna manera extraer de muchas entidades lo mejor y lo pones en la LPAG. No es el camino a la inversa: no es poner algo en la LPAG para ver cómo funciona en el resto de la Administración Pública. Eso sería un poco arriesgado y poco estratégico, digamos.

Cuando se incorporó a la Ley, el régimen de fiscalización se hizo viendo cómo funcionaba la fiscalización minera, laboral, ambiental, de 
los organismos reguladores. Viendo todas esas, viendo cuales eran las practicas más importantes de derechos, obligaciones, deberes, etcétera, se trató de consolidar y mejorar. Entonces, lo que está en la ley me parece que es bastante actual. Menciono también que es novedoso en derecho comparado, ya que ahí no hay un régimen centralizado de fiscalización. Hay varios países que recién nos están tomando la idea y están tratando de desarrollarlo en sus países, y me parece que es bastante reciente.

Sí hay algo que actualizar, pero no diría que es urgente o indispensable. Yo haría algún ajuste, o algún agregado sobre la fiscalización tecnológica o fiscalización a través de medios informáticos. A raíz de la pandemia se ha comenzado a utilizar la fiscalización electrónica, la fiscalización por video vigilancia y ya no se habla de, y en la práctica ya no se ven las fiscalizaciones típicas manuales que se hacían con actas escrituradas del funcionario público yendo a una oficina, levantando un acta y documentando. Además, la fiscalización se traduce en pruebas, evidencias, y esa evidencia ahora es más virtual que escrita. Entonces, quizás esa es la parte de la Ley que podría modificarse. Obviamente no podíamos prever la pandemia ni tampoco los avances tecnológicos, pero eso no está la Ley. Hay muchos sectores actualmente que hacen fiscalización, a través de medios informáticos que no tienen regulación. Cada entidad lo está regulando como puede y están ocurriendo algunos desajustes ahí. Pero, repito, no es un tema de vida o muerte. Para hacerlo, podría ser a través de un Decreto Supremo, podría ser una norma adicional, etcétera, para dar un régimen más o menos unitario.

JD: A ver, en la misma lógica de buscar no repetir lo que ha comentado ya el doctor Morón, la actividad de fiscalización se buscó regular por la misma razón por la cual se reguló, por ejemplo, el sancionar y el trilateral: para proporcionar en buena cuenta un mínimo común denominador transversal en una actividad que en los últimos años se ha convertido en muy importante. Así como se reguló el sancionador y el trilateral, también se constató la necesidad de proponer una regulación sobre esta potestad.
Además, en la legislación había mucha diversidad en su denominación. Se hablaba de supervisión, fiscalización e inspección como si fueran potestades diferentes y para la Ley es lo mismo: una potestad, supervisión, administración, inspección es lo mismo. Como comentó el doctor Morón, a partir de la regulación especial hay que establecer cuál es el común denominador que la Ley considera que debería garantizar la actuación de la administración, en el ejercicio de esta potestad.

Hay una parte de la pregunta de ustedes sobre si hay un desequilibrio entre la posición de la administración y el administrado. Yo no sé si es correcto hablar de desequilibrio porque, yo cuando menos, parto de la idea de que siempre hay un desequilibrio. La ley le puede dar prerrogativas a la administración, dentro del marco legal constitucional, que no tiene el ciudadano. Estas son prerrogativas exorbitantes. Lo que pasa es que no son prerrogativas que sean implícitas o que estén ya consideradas tacitas, siempre tienen que estar expresas en el marco legal porque son prerrogativas que el ordenamiento jurídico legal le da a la administración para facilitar y garantizar que cumpla precisamente con la realización de los intereses de la colectividad. Por lo tanto, yo parto de que esta desigualdad, dentro del marco de constitucionalidad, dentro del marco legal, siempre también garantizando los derechos, no es extraña y no es irregular.

Entonces lo cierto es que, si la pregunta fuera si es que no se están garantizando adecuadamente los derechos de los administrados en la regulación considerada en la Ley de procedimiento de fiscalización -yo prefiero hablar de procedimiento en lugar de actividad de fiscalización-yo creo que sí. Yo creo que sí se están garantizando, por eso el marco legal le establece facultades, deberes, derechos a la administración. Hay un conjunto de principios en general en la LPAG, por tanto, las garantías están, más allá de los problemas que puede haber en la aplicación práctica del día a día, que en todo caso el afectado lo podría impugnar, pero no veo un problema, así como está. 
Como comentaba el doctor Morón, falta un poco más de tiempo para poder ver cuál ha sido la experiencia, y probablemente también qué ocurre con la regulación especial, con las regulaciones que pueden dictar por ejemplo los reguladores y otras entidades a nivel norma reglamentaria, ver cómo es que tienden a adecuarla. Tengo la impresión de que incluso las entidades que tienen potestad normativa propia tienden a sujetarse más a la regulación de la actividad del procedimiento de fiscalización. Pero yo no veo que haya en la Ley, como está regulado, un desequilibrio que puede perjudicar la posición del administrado.

Respecto de las mejoras que pueden realizarse, coincido con el doctor Morón en que hay que atender, a futuro, lo relativo a la fiscalización por medio digital. Ello porque ya las experiencias van demostrando que es necesario y probablemente otra vez volvamos, para terminar mi comentario, al tema de la necesidad de ir acotando estas posibilidades de, salvo cuando sea indispensable, apartarse del régimen general de fiscalización considerado en la ley de procedimiento administrativo.

Probablemente algún otro tema tenga que ver con el régimen de las medidas correctivas o de aseguramiento o de emergencia que se pueden dictar con motivo de la fiscalización, que la Ley avanzó en su artículo 246 a establecer algunas reglas sobre las cautelares y correctivas que se pueden dictar durante la fiscalización diferentes a las que se dictan con motivo de la potestad sancionadora. Creería que probablemente ese es otro tema el cual también habría que revisar a futuro para poder mejorar.

4. La LPAG contiene garantías mínimas que deben ser respetadas en todos los procedimientos administrativos, incluidos los especiales. Sin embargo, muchos operadores administrativos, bajo el principio de especialidad, no han respetado ese piso mínimo común y han establecido garantías distintas, por ejemplo, respecto a los plazos de prescripción. ¿Cómo puede resolverse el conflicto entre la LPAG y los regímenes especiales respecto a las garantías?
JD: Hace un momento comentamos sin querer esto y lo cierto es que sí se constatan estas tendencias centrífugas de parte de algunas entidades de querer zafarse de la regulación general y no necesariamente porque la especialidad de la materia lo justifique, porque eso se entendería perfectamente, sino simplemente porque no se sienten cómodos de alguna manera. Algunos incluso han manifestado por escrito que les parece que la Ley es muy garantista, es decir que ellos entienden que la administración debe estar dotada de prerrogativas y potestades y que a veces los derechos incomodan a la actuación administrativa. Eso es incomprensible porque es no entender precisamente que el Derecho Administrativo y el procedimiento administrativo nace precisamente con ese fin, de establecer un conjunto de garantías, de facilitar el trabajo de la administración, pero con las garantías hacia los ciudadanos.

Entonces, ¿qué sucede? ¿Por qué estos operadores tratan de apartarse? Lo han hecho en algunos casos por cercanía a las entidades que han manejado en buena cuenta las facultades para dictar normas, sobre todo cuando han existido facultades legislativas delegadas. Éstas han sido manejadas principalmente a través de algún ministerio más que otro, como el Ministerio de Economía, y uno puede constatar como han sido las entidades bajo el sector economía las que han tenido mayor facilidad para poder pedir que se dicten Decretos Legislativos que les permiten apartarse en buena cuenta, de estas normas. Para no hablar de otras como Contraloría, que lo han hecho por vía legal.

Esto, en tanto que no tenga un fundamento por razón de la materia de especialidad sino solamente por comodidad, es obviamente criticable. Pero la pregunta es ¿cómo puede resolverse el conflicto entre la Ley y los regímenes especiales respecto de las garantías? Tengo la impresión de que en estos 20 años la LPAG se ha convertido de verdad en el referente que toma en cuenta la persona como el conjunto de garantías que tiene en su plato frente a la administración. Entonces, entiendo que el destinatario de la actividad administrativa es el que tiene que reclamar y tiene que demandar que se respeten esas garantías 
de la ley general. Alguien podría pensar que eso es ley versus ley, bueno, lo que ocurre es que hay que ver cuáles de estas garantías tienen un fundamento constitucional.

La LPAG en su artículo segundo, que habla de su contenido, dice que las leyes especiales no pueden imponer condiciones menos favorables - y las normas que regulan lo sancionador también dan a entender cómo es que estos principios de lo sancionador prevalecen sobre normas especiales-. Sin lugar a dudas, el privado afectado por esta disparidad en buena cuenta tendría que reclamar ante la administración aquello. El administrado tendría que fundarse, además de en lo que dice la ley general y lo que dicen las normas especiales, en que la mayor parte de estas garantías tienen un fundamento constitucional. Por ello, el administrado debería invocar el fundamento constitucional que tienen las normas para poder reclamar ante la administración. No la inaplicación, no el control difuso - la administración no puede hacer control difuso de leyes - sino más bien lo que podría reclamar es una interpretación y aplicación de la norma especial conforme a la constitución y al desarrollo que conforma la constitución.

Termino con esto, estos problemas se pueden estar planteando principalmente respecto de algunas entidades a las cuales la ley les ha dado facultades normativas internas. Hay entidades en las cuales el marco legal - debido a la especialidad o carácter técnico- les ha dado facultades para regular procedimientos y para regular potestades y ahí es donde se pueden generar conflictos. Pero, sin duda alguna, esas normas que se dictan en base a una ley deben estar subordinadas a lo que establece la constitución y el conjunto de principios de origen constitucional que se enuncian en la LPAG.

JCM: Lo que ustedes han constatado es correcto. Existe una tendencia a ello, no de ahora como comentaba al inicio, sino desde antes de la ley. Eso era común, teníamos un Reglamento General de Normas de Procedimiento Administrativo, que era supletorio, en defecto quedaba ese reglamento. Ese era el estado de la norma anterior.
La Ley del Procedimiento Administrativo entró para cambiar eso, no del todo en la primera versión porque la original también hablaba de que había procedimientos especiales, leyes especiales que se podían salir, pero demandaba una ley expresa. Pero las entidades conseguían leyes expresas.

La última modificación de la LPAG cambió el esquema y lo que hizo fue que la LPAG ya no sea una ley general, aunque el nombre se quede - Ley del Procedimiento Administrativo General-, ahora es una norma común, es decir es un mínimo común múltiplo, por decirlo en términos alegóricos, para todas las entidades públicas.

No hay ninguna entidad publica que pueda decir "de esta regla me exceptúo, esta regla no me cae, yo soy especial y yo utilizo una regla distinta." Menos si la sacan por directiva, reglamento o práctica, eso es ilegal. El último cambio que se hizo de la Ley hizo ilegal entender que por reglamento o norma subalterna alguien puede tener una norma distinta. Cuando se ha mencionado los plazos para impugnar, plazo de prescripción, etcétera estos son casos que no deben darse porque la Ley ya regula el tema y dice que no puede haber norma distintiva.

No puedo dejar de mencionar algo, la pregunta que ustedes han planteado es uno de los problemas mas típicos del Derecho Administrativo, porque el Derecho Administrativo parte de algo que algunos llaman ilusión, otros expectativa: este derecho es para controlar el poder, eso es lo que el Derecho Administrativo quiere. Ello no para que impedir que actúe, porque el poder público busca el interés público y colectivo, la protección de las garantías generales. Lo que se quiere es que el sector público actúe dentro de la ley para lograr cometido público respetando los derechos fundamentales. Sin embargo, es muy difícil de lograr, por eso algunos dicen que es una ilusión. Pero cuando un funcionario publico dice "yo soy especial, no hago caso a la norma" es un fenómeno de poder, un funcionario público que tiene poder esta queriendo decir "yo no hago caso a la ley". Entonces, ahí quienes deberían actuar son los mecanismos 
del propio Derecho Administrativo - sanciones, responsabilidades, el ciudadano reclamando, etcétera-, incluyendo el proceso contencioso administrativo donde el juez sanciona al funcionario. Uno de los temas carentes en otros países es la responsabilidad funcional, si no funciona la responsabilidad se pueden dar esos incumplimientos de la ley de manera dolosa.

5. Existen figuras como la queja administrativa que son desconocidas por los administrados, sin embargo, suelen ser herramientas útiles para conseguir que la administración resuelva dentro de los plazos previstos. ¿Considera usted que deberíamos mejorar la regulación de estas figuras y visibilizarlas más?

JCM: A ver, de manera general y después vamos con el tema de la queja. Yo creo que la LPAG tiene todavía instituciones que no se han desarrollado cabalmente, están latentes en la norma y será cuestión de ponerlas en el ordenamiento. Yo siempre repito que hay un artículo en la Ley que establece que las entidades públicas deberían trabajar en horarios no coincidentes con el horario de trabajo de la ciudad. La ciudad trabaja normalmente de 9 a 5 o de 8 a 4 . La administración trabaja el mismo horario, entonces los ciudadanos, cuando había presencialidad y uno tenía que hacer un trámite, no encontraban la Administración Pública o tenían que faltar al trabajo. Entonces la Ley tiene una norma y esa es que la Administración Pública trabaja por turnos y trabaja en horarios no coincidentes con el sector privado. Eso significa que, como en otros países sucede, la Administración Pública trabaja, no 24 horas, pero si trabaja pues hasta las 7, 8, 9,10 de la noche por turnos y los ciudadanos sí pueden acceder a los servicios en conformidad sin faltar a tu trabajo. Esa es una norma que está en la Ley, nunca se aplicó. Así, hay cosas en la Ley que no se aplican porque simplemente nadie lo ha detectado, nadie ha hecho una campaña, nadie la defiende y ahí está.

Ahora en la regla que ustedes plantean de la queja, este es un instrumento típico de defensa del ciudadano frente a la mala praxis de los funcionarios de no resolver, de descontar los expe- dientes, de no permitir el acceso, de engañar a los administrados, al ciudadano. Lo que sucede con la queja - que no es un tema jurídico, es un tema práctico- es que, así como solemos decir que en el Congreso hay este espíritu de cuerpo entre los congresistas, en la función pública también hay eso, es decir, el espíritu de cuerpo entre los funcionarios. Entonces si a quien vas a quejar es al superior jerárquico del que ha incumplido la falta, todos son del mismo grupo, del mismo partido, son primos hermanos, entonces no funciona mucho y a veces sucede en algunas entidades, lamentablemente, que actúan bajo ese estricto cuerpo donde si tú te quejas te ven mal, entonces te rechazan tu reclamo.

Entonces, no es que haya un incentivo hacia que la queja funcione. Si en mi ejercicio profesional he utilizado la queja un par de veces, es mucho. A los clientes, tú les dices "hay que quejarse" y responden: “¡No! ¿para qué? si después me van a ver mal y van a decir que no, me van a rechazar." "Que venga el Poder Judicial a liquidarlos." "Esperamos un ratito más, mejor tratemos de convencer."

Ahí ya es un tema psicológico, digamos, el porqué no funciona la queja. Pero de que existe en la Ley está, en todos los reglamentos jurídicos está y tengo la impresión de que no en muchos países funciona bien. Es por este tema de los espíritus de cuerpo que existe en estas entidades públicas. A veces funciona mejor la denuncia al orden del control interno, la denuncia a Contraloría que tiene un poquito más de independencia respecto del funcionario de la propia entidad pública que recibe la queja. No sé si Jorge tenga algo qué mencionar.

JD: Gracias Juan Carlos, vamos con un tema puntual: creo que todos sabemos que una ley per se no cambia la realidad. La ley establece reglas para la actuación de la administración y también empodera al destinatario de la actividad administrativa, al ciudadano, para que pueda reclamar, quejarse, insistir, impugnar y procurar que la administración actúe de acuerdo con el cumplimiento de sus funciones y al servicio del ciudadano. La administración es una organización al servicio de. No existe porque hay un mandato 
divino, sino se crea para que tutele, para que realice los intereses que la colectividad le encargue, para que ejecute las políticas públicas por las cuales la ciudadanía ha elegido gobernantes.

Pero, ¿qué sucede? Hay una cultura administrativa. Por lo tanto, para mejorar el funcionamiento, tenemos que notar el cambio de la cultura administrativa. Si usted me preguntara, por ejemplo, si la recepción de la LPAG ha sido igual y el nivel de aplicación es igual en todas las entidades administrativas, le diríamos que no. A un nivel municipal te reclaman mayor. ¿Por qué razón? Bueno, porque en la cultura administrativa, a un nivel municipal, - no en todos por supuesto, hay muchos modernos - lo que hay es la búsqueda de recursos, la búsqueda de tener ingresos - que actualmente son insuficientes para la entidad-y por parte de algunos funcionarios hay un rigorismo procedimental forzado. En estos casos el procedimiento administrativo no parece ser el cauce para cumplir sus funciones, sino el conjunto de trámites que hay que hacer. No importa para que, hay que seguir los trámites.

Esta suerte de rigurosidad formalista proviene por desconocimiento, por una falta de poder de la administración en muchos casos, o porque los órganos de control lo estimulan ya que les resulta mucho más fácil controlar la forma, el rigorismo formal. A lo que quiero ir es a que hay una serie de distorsiones, también en la cultura administrativa, que hacen que, en ocasiones, de esa base sobre la cual tiene que aplicarse la LPAG no siempre se obtenga el resultado esperado. Es decir que este rigorismo formal, esta necesidad de tener recursos, el actual miedo que está muy extendido en el funcionario público, lo que está haciendo es que el funcionario pierda el norte. Lo que debería ser lo principal en el funcionario, cumplir el rol que venimos conversando de realizar y cautelar los intereses públicos, no se convierte en su objetivo principal y por lo tanto los mecanismos e instrumentos que establece la ley no siempre se cumplen por parte del funcionario.

Más bien lo que hace la Ley, como comentaba el doctor Morón, es empoderar al destinatario de la actividad administrativa para que sea él quien tiene el rol activo demandando la aplicación de la garantía prevista por la Ley y demandando que el funcionario cumpla su rol. Que tenga en cuanta que el procedimiento no es un conjunto de fases o trámites únicamente que se tengan que cumplir, más bien, es un mecanismo que le permite a la administración cumplir su rol, cumplir su objetivo, cumplir su función y eso a veces se pierde de vista.

En la Ley hay mecanismos, y si no están ahí también están en otros mecanismos jurisdiccionales -en lo que el ordenamiento jurídico establece o la Constitución proclama-. Están ahí, pero también hay que apostar por mejorar en buena cuenta la cultura administrativa que sirve de base para el funcionamiento de la administración y eso es un tema que supera a la propia LPAG en ocasiones y lo estamos padeciendo en los últimos años.

\section{6. ¿Qué considera usted que le falta la LPAG para responder a las necesidades de la sociedad actual?}

JD: Siendo muy puntual, hay un tema que el doctor Morón ha estado discutiendo en conferencias, un tema que lo estamos viviendo a partir de la pandemia, que genera una serie de distorsiones y que además hay un común denominador a nivel mundial: avanzar hacia un régimen general de digitalización en materia de los procedimientos tomando en consideración que no basta con el mero enunciado legal. Como el doctor Morón lo ha escrito, puede suceder que en términos políticos o en términos, en muchos casos de demagogia, alguien crea que va a estar regulada en la ley sin considerar que hace falta equipamientos, capacitación, cambio del funcionario y también facilidades a los funcionarios de la actividad administrativa en materia de digitalización. Aquí se cree que la digitalización consiste en tener una mesa de partes virtual y una notificación electrónica. "Se acabó, ya hicimos un cambio en la digitalización." Eso es demagógico. Lo cierto es que es un proceso mucho más general, más amplio. Es un cambio de la cultura de la administración de enfatizar el servicio del ciudadano y eso no se está entendiendo. 
En un plano meramente legal, hoy día lo que está sucediendo es que la digitalización de los procedimientos administrativos, si bien la Ley contiene algunas normas generales - contiene las bases-, está corriendo en paralelo, está corriendo por normas reglamentarias que se dictan a partir de la Presidencia del Consejo de Ministros. Y claro está, el problema de regular con carácter general también es la diversidad de la organización administrativa de nivel nacional, regional y local $-y$ aún dentro del local hay diversos niveles de organización-. Entonces, el tema tiene que avanzarse hacia una regulación en la ley general del tema digital. El doctor Morón de seguro va a ahondar muchísimo más en eso.

¿Qué otros aspectos? Probablemente reforzar el tema del carácter común y precisar en qué aspectos es de carácter común la Ley para evitar las fugas de las que venimos conversando de algunas entidades administrativas. He de señalar que son los principios, el régimen del acto administrativo, el régimen de los mecanismos de revisión y el régimen de la potestad sancionadora y fiscalización como algunos de los temas.

Otro tema adicional es que en el Perú venimos hablando los últimos años, con un énfasis particular, de la responsabilidad disciplinaria y sancionadora del funcionario. Una forma punitiva de la administración al funcionario. Contraloría y la fiscalía vienen actuando sin entender como funciona la Administración Pública. Sin embargo, lo que no tenemos es una garantía importantísima del derecho comparado que es la responsabilidad de la Administración frente al privado. Ya no la responsabilidad solo del funcionario, de la cuál nos ensañamos y generamos las distorsiones de las cuales venimos conversando, sino de la administración como la empleadora, y que el funcionario responda frente a la administración sobre los daños frente al privado.

Eso está enunciado en la Ley y es el estándar a nivel mundial, pero en el Perú no hay la cultura, ni judicial y administrativa, y tampoco son muy conscientes las personas de ello. Eso es otro tema por desarrollar que puede ser parte de la
LPAG. Hoy día no lo es, pero es una de las tareas pendientes de garantía del privado frente a la administración y también estimula a que la administración actúe bien cuando es consciente que debe resarcir los daños y que el administrado puede repetir contra el funcionario también en esos casos. Sin embargo, en el Perú hemos preferido la responsabilidad institudinaria, en el énfasis cognitivo sobre el funcionario, pero no en el resarcimiento de la administración de los daños. Probablemente este sea otro tema para pensar a futuro.

JCM: Coincido bastante con los temas que planteó Jorge, creo que el tema de la administración electrónica es necesario, pero lo que yo diría no es una gran reforma, no es incurrir a capítulos sobre administración electrónica. Se trata de incluir los grandes temas importantes de la administración electrónica en la Ley. Por ejemplo, notificación. La Ley tiene la regulación tradicional en la notificación física, se introdujo una reforma sobre la notificación electrónica pero muy mala. De la regulación no queda muy claro si la notificación es una obligación o un derecho de los ciudadanos, parece entenderse por muchas entidades públicas que es una obligación.

Algunas entidades públicas, lo que están haciendo, es que abren un correo en su servidor propio y te dicen "a partir de la fecha, tú date por notificado porque yo voy a depositar los correos en este servidor." Así, todos los ciudadanos tienen que ir a recorrer entidad por entidad para ver en qué entidad le han notificado algo y esa no es la idea, eso en ningún país funciona. Ese es un tema.

Creo que hay que pensar en muchas instituciones del procedimiento administrativo, no solamente en lo físico como estuvieron pensados en la ley del 2000, sino en lo virtual y pensarlas también de manera garantista, es decir que no pierdan su naturaleza de garantía porque sino la lógica del procedimiento va a perjudicarse.

Igual, por ejemplo, pensamos en el expediente electrónico. La Ley se modifica para agregar un expediente electrónico, pero ¿qué más hay sobre el expediente electrónico? Siempre hay una 
definición que indica que el expediente electrónico es igual que el expediente físico pero convertido en medios virtuales, pero ¿cómo se conforma? ¿de quién es la responsabilidad armarlo u organizarlo? No es un conjunto de PDFs en un $C D$, eso no tiene ninguna lógica. Entonces esos temas creo que implican repensar la Ley en función de la tecnología y ver que temas hay que regular. No es una gran reforma, no es un gran capítulo, es institución por institución a ver cuáles deben tener algún ajuste.

Estoy pensando, y esto es una reflexión en voz alta, si es que amerita crear en Perú, como sucedió en otros países, una defensoría del ciudadano sobre la administración electrónica a quién poder quejarse cuando uno es discriminado por la Administración Pública o la administración electrónica. En algunos países ha funcionado eso. Nosotros, ahora que estamos pensando en las distintas culturas que tenemos en el Perú, estamos viendo las distintas realidades que hay en el país y yo imagino que si comenzamos a utilizar administración electrónica en zonas donde no se tiene conectividad entonces exigir ello es ilusorio. Ese es un tema que debemos revisar.

Otro tema con el que coincido con Jorge es el de la responsabilidad. Yo echaba vista al índice de la Ley y el título $V$ tiene dos capítulos. El capítulo de la responsabilidad de las autoridades y personal de servicio de la Administración Pública tiene cinco artículos. Esos cinco artículos están cada día más en desuso porque ya la responsabilidad del personal de las entidades públicas está regulada por otros regímenes - por la Ley SERVIR y por las normas especiales de carrera-. Creo que eso hay que revisarlo para ver si justifica mantenerse, y en que medida. Pero lo que sí hay que modificar es el artículo 258 de la Ley que regula la responsabilidad de la Administración Pública, en qué medida y cuándo es responsable esta frente a los daños.

Uno de los aspectos en donde la Administración Pública o el Estado pierde legitimidad es cuando el particular se siente afectado por la Administración Pública y esta no le resarce sus perjuicios. Un mal servicio médico de una dependencia pública, la falta de servicio de tele- comunicación, del servicio de salud, del servicio de educación. No hay, digamos, espacio en el cuál el ciudadano pueda reclamar, con un nivel de expectativa que tal vez resarzan los daños.

En temas tan menores, hay mucha gente de la ciudad que tiene pequeños negocios, se le ocurre un día a la municipalidad romper la pista, evitar que el público pase por esa calle, le evitan el tráfico en esa calle por meses a la empresa y el comercio que uno pone se extingue porque nadie va a esa zona y nadie le resarce el daño simplemente quebró y quebró. En esta pandemia, ¿cuántos casos hemos escuchado de gente que tiene en su casa respiradores domiciliarios, se les fue la luz y el paciente no lo pudo soportar? ¿Quiénes resarcen ese daño? ¿Dónde se analiza? Simplemente lo que tenemos es un conjunto de personas insatisfechas con el Estado que después se van contra él, reclaman contra él y lo quieren cambiar, porque no hay un mecanismo de responsabilidad.

En los grandes casos en temas de responsabilidad que nosotros escuchamos - por ejemplo, las matanzas que el Estado realizó a estudiantes universitarios durante la época del terrorismo- los grandes mecanismos de indemnización no han venido de la jurisdicción nacional, estos han venido de ciudadanos que se han ido a la Corte Interamericana y ésta logró la condena al Estado a resarcir los daños y los perjuicios ocasionados. El Perú no fue capaz de sancionar eso, el Perú no fue capaz de sancionar a alguien, decirle en efecto "págale, porque le has cometido un perjuicio," y eso es tema de la LPAG. Está el artículo de responsabilidad civil y patrimonial del Estado, pero no se utiliza. La norma está mal y tampoco hay una cultura de responsabilidad, hay una cultura de evasión. Entonces creo que esos son ejemplos de un tema importante, no sé si haya la voluntad política de asumirlo, pero creo que hay que hacerlo.

Por último, algo que para mí es curioso, no me cansaré de decirlo, es el tema de estructurar un correcto sistema de combate a las barreras burocráticas porque eso es, para mí, un sinsentido. Por ejemplo - para contarles un ejemplo senciIlo-, el Estado ha dictado una norma que dice 
que ninguna entidad pública puede cobrar, por tasa, más de una Unidad Impositiva Tributaria - UIT. Eso es una regla sencilla, tiene excepciones, pero es la regla general. Esa norma la pone el Estado y el propio Estado la incumple porque las entidades públicas no le hacen caso y aprueban, en sus Textos Únicos de Procedimiento Administrativo, tasas por encima de una UIT. Ojo que el Estado puso la norma, el Estado la incumple, y cuál es el sistema: obligar al ciudadano a ir y reclamar a otra entidad publica que se llama INDECOPI. Una entidad pública para que resuelva el problema de otra entidad pública. Y a ese ciudadano, ¿qué le pide INDECOPI? Le pide una tasa, que el ciudadano tiene que pagar en cada caso para ir a reclamar. Ello demora meses y dos instancias. Al final, INDECOPI puede resolver algo y la entidad se va al Poder Judicial a través del proceso contencioso administrativo porque no está de acuerdo con lo resuelto y recién ahí se acabó todo.

No es un sistema que parece eficiente para combatir barreras burocráticas por un tema tan sencillo como una UIT. El privado no va a estar con un bolsillo de dinero para pagar instancias y tasas. ¿Qué es lo que hace el ciudadano? Un ciudadano frustrado lo que hace es pagar la UIT, hace su trámite administrativo y al diablo.

Entonces, ese sistema no me parece que sea eficiente, no me parece que responde en verdad a un combate franco a las barreras burocráticas. Nos engañamos y nos causamos mucha frustración. Ese es un tema que para mí valdría la pena reexaminarlo, no está propiamente en la Ley, quizás habría que realizarlo e incluirlo, pero de manera eficiente para que no sea lírico. 